\title{
The comparison of general movements assessment and neurological examination during early infancy
}

\author{
Büşra Kepenek-Varol${ }^{1}$, Mine Çalışkan², Zeynep İnce ${ }^{3}$, Burak Tatlı², Emine Eraslan², \\ Asuman Çoban ${ }^{3}$ \\ ${ }^{1}$ Department of Physiotherapy and Rehabilitation, Bezmialem Vakif University Faculty of Health Sciences, ${ }^{2}$ Divisions \\ of Pediatric Neurology, and Neonatology ${ }^{3}$, Istanbul University Istanbul Faculty of Medicine, Istanbul Turkey. \\ E-mail: busrakepenek@gmail.com \\ Received: 22 March 2016, Revised: 6 April 2016, Accepted: 6 May 2016
}

SUMMARY: Kepenek-Varol B, Çalışkan M, İnce Z, Tatlı B, Eraslan E, Çoban A. The comparison of general movements assessment and neurological examination during early infancy. Turk J Pediatr 2016; 58: 54-62.

This prospective single-blinded study was performed to evaluate general movements (GMs) in group of high-risk, low-birth-weight and preterm infants and to compare results with neurologic examination. All infants' neurologic examinations, Gross Motor Function Measurement (GMFM) and Bayley-III Scale were performed at the corrected age of 12 months. A total of 22 infants were included. Eight infants (group-1) (mean: 31.6 \pm 3.29 weeks, range: 25-36 weeks) had normal GMs in all recordings and were ultimately evaluated as "normal"; 12 (group-2) (mean: 31.6 \pm 3.29 weeks, range:2 5-35 weeks) had abnormal GMs during writhing movements period but had normal GMs in subsequent recordings and were evaluated as "normal"; and 2 infants (group-3) (mean:29.5 \pm 7.78 weeks, range:24-35 weeks) with consistent abnormal GMs who were evaluated as "abnormal." Complete agreement (kappa $=1)$ was found between GMs and neurologic examination and significant agreement between GMs and cranial ultrasonography $($ kappa $=0.76)$. When results of GMFM and Bayley-III were compared; statistically significant differences were found between group-1 and group-2 in "standing" parameter of GMFM $(p<0.05)$ and "cognitive" parameter of Bayley-III ( $\mathrm{p}<0.05)$. GMs assessment can help determine neurologic disorders in high-risk infant populations as an adjunct to other diagnostic techniques.

Key words: general movements, preterm infants, low birth weight, neurological examination, Bayley-III.

Prematurity and low-birth-weight (LBW) are the most important risk factors for abnormal neurologic outcomes. Cerebral palsy $(\mathrm{CP})$ is an important neurologic disease that has higher prevelance and has an effect on decreasing maturity following preterm birth. Extremely preterm infants (postmenstrual 22-32 weeks) have the highest risk for $\mathrm{CP}^{1,2}$.

Prechtl's method on the qualitative assessment of general movements (GMs) has proven to be a valid and reliable technique for the functional assessment of the immature nervous system. Several studies have shown that the analysis of GMs plays a major role in predicting the neurologic outcome of premature infants ${ }^{3-10}$. Subsequent fetal studies on the importance of different prenatal movement patterns revealed an onset of GMs at 9 weeks postmenstrual age. GMs continue to be present during the entire prenatal period until approximately 5 to 6 months post-term ${ }^{11}$.

Recent studies focused on the relationship between GMs and cognitive function, behavioral problems or minor neurologic dysfunction ${ }^{12-13}$. The aim of this study was to evaluate GMs in a group of preterm LBW infants, and to compare the results with neurologic examination findings.

\section{Material and Methods}

This prospective study was planned and performed as single-blind in a preterm infant 
cohort in the Division of Child Neurology Unit and Neonatal Intensive Care Unit, Istanbul Medical Faculty, Istanbul University between 2011 and 2013. The study was approved by the Ethics Committee of the Faculty of Medicine, Istanbul University, 1769 in 03.11.2011. Informed consents were received from parents.

\section{Patients}

Preterm LBW infants whit a gestational age of $<37$ weeks and birth weight $<2500 \mathrm{~g}$ in the Neonatal Intensive Care Unit (NICU) were included in the study. The exclusion criteria for the study were; infants with congenital malformations, genetic and metabolic diseases, ongoing mechanical ventilation therapy, and infants whose parents did not want to participate in the study. Twenty-two preterm low-birth-weight (LBW) infants (14 girls and 8 boys) were included in the study. After the following assessments, the infants were divided into groups according to GMs results. Group 1 included 8 infants who had normal GMs in all recordings and were ultimately evaluated as "normal"; group 2 comprised of 12 infants who had abnormal GMs during writhing movements period (38-48 weeks postmestrual age) but had normal GMs in the following recordings and were ultimately evaluated as "normal"; and group 3 constituted of 2 infants who had consistent poor repertoire (PR) GMs and cramped-synchronized (CS) GMs, and absent fidgety movements (FMs) in the fidgety period (46-60 weeks postmenstrual age), who were ultimately evaluated as "abnormal."

\section{Assessments of general movements (GMs)}

A video camera was stabilized on a tripod and the infants were filmed midsagittally or laterally from above. The video recording period was 20-30 minutes for preterm and writhing movements and 10-15 minutes for the FMs period, excluding crying, fussing or sucking durations. During recording periods the infants were in a supine position in the incubator or on the bed depending on their ages. Any stimulus that could affect GMs was avoided, such as mirrors, toys or communication with parents. The infants were required to wear thin vests with arms and legs bare or only with diapers. The room/incubator temperature were adjusted according to the infants needs.

General movements involve the whole body in a variable sequence of arm, leg, neck, and trunk movements. The movements of the different body parts do not occur in a complex way as seen in normal GMs during preterm, term, and early postterm age (first two months). GMs are called preterm GMs before term and "writhing movements" from term until approximately 6-9 weeks post-term. The form and character of GMs of normal infants, 6 to 9 weeks post-term, change from the writhing type to a fidgety pattern ${ }^{11,14}$. The types of normal GMs are defined as follows:

Preterm GMs: Preterm infant may occasionally have large amplitude GMs that are often fast in speed.

Writhing movements: These movements are characterized by small to moderate amplitude with slow to moderate speed.

Fidgety movements: FMs (46-60 weeks postmenstrual age) are small movements with moderate speed and variable accelariton of the limbs, trunk, and neck in all directions in the awake infant, without fussing and crying. FMs are present until around 6 months of age when intentional and antigravity movements occur and start to dominate ${ }^{11}$.

The types of abnormal GMs are defined as: PR GMs, CS GMs, and chaotic (Ch) GMs (Table I). If the nervous system is impared, FMs can be either abnormal or absent. A GMs-certified physiotherapist, recorded the videos of the spontaneous motor activities of infants from birth until corrected 5 months of age. No video recording was performed in the first 3 days of life because there are many physiologic and behavioral state fluctuations in this period of newborns ${ }^{11}$. Two to five video recordings were obtained for each infant in our study. The 1st (29-31 weeks), 2nd (32-37 weeks), and 3rd (38-44 weeks) recordings were examined for "preterm and writhing movements," and the 4 th (48-50 weeks) and 5th (50-55 weeks) recordings were evaluated for FMs.

The evaluating physiotherapist was blinded to the prenatal and postnatal history of the infant. The findings were classified as normal $(\mathrm{N}), \mathrm{PR}$, or CS in the writhing period, and as normal fidgety $(\mathrm{N})$, abnormal fidgety (AF), or absence of fidgety (F-) movements in the fidgety period.

The first assessments of the study cohort were 
Table I. Abnormal General Movements ${ }^{11}$

Poor Repertoire GMs (PR)

Cramped-synchronized GMs (CS)

Chaotic GMs (Ch)

Abnormal FMs

Absence of FMs
Movements of different body parts do not occur in the complex way seen in normal GMs and whereby the sequence of GMs is monotonous; speed, amplitude and intensity lack the normal variability

This abnormal GMs pattern appear rigid as they lack usual fluent character and muscles contract and relax almost simultaneously.

In this pattern movements consistently appear jerky and occur in large amplitude and high speed.

Amplitude and speed of FMs are exaggerated. These movements are seen rarely.

FMs could not observe.

GMs: General Movements, FMs: Fidgety Movements

made by observing the GMs only. The patients were classified as normal or abnormal according to GMs results. After a one-year follow-up period, the prenatal and postnatal history of the patients, including examinations such as cranial ultrasonography, were reviewed from their data to provide bias about the clinical status of the patients before assessments.

\section{Developmental outcome measures}

At corrected 12 months of age, reflexes and motor development of infants were examined by a specialist of child neurology who was blinded to the study groups. The Modified Ashworth Scale (MAS) is the most commonly used clinical measure of muscle spasticity ${ }^{15}$. In the present study, muscle tone was evaluated while infants were in supine position using MAS. The following muscles were evaluated using MAS: musculus (m) biceps brachii, m. triceps brachii, m. iliopsoas, adductor muscles of the hip (m. adductor longus, m. adductor brevis, $\mathrm{m}$. adductor magnus, $\mathrm{m}$. gracilis), hamstrings ( $\mathrm{m}$. biceps femoris, $\mathrm{m}$. semitendinosus and $\mathrm{m}$. semimembranosus), m. gastrocnemius.

Motor development was assessed using Gross Motor Function Measurement (GMFM). GMFM is commonly used to measure changes in gross motor function and to enable the development of scientific research studies on children with CP. The GMFM consists of 88 items in five dimensions: supine-prone (lying and rolling), sitting, crawling-kneeling, standing and walking-running ${ }^{16}$. In our study, supineprone, sitting, crawling-kneeling and standing parameters of GMFM were used.

The Bayley-III Scale was used to assess motor, cognitive, and language development.
The latest revision of the Bayley-III Scale is commonly used to identify infants at risk for developmental impairment and includes distinct composite scores: cognitive, language, and motor ${ }^{17}$.

\section{Statistical analysis}

Qualitative variables are presented as percentages and quantitative variables are shown as means with standard deviations. Cohen-Adjusted Kappa was used to correlate the assessment of GMs, cranial ultrasonography, and neurologic examinations. The percentage agreement ratio of 0.20 was accepted as nonsignificant, $0.21-0.40$ as minimal agreement, $0.41-0.60$ as moderate agreement, $0.61-0.80$ as significant agreement, and $0.81-1.00$ as complete agreement ${ }^{18}$. The Mann-Whitney U test was used to compare differences between the groups, and statistical significance was accepted as $\mathrm{p}<0.05$.

\section{Results}

At the beginning of the study 38 infants were eligible for the assessments. Sixteen were excluded from the study because they did not complete their follow-up assessments, and one died. Twenty-two high-risk infants (14 girls, 8 boys) were included in the final assessment. The gestational age ranged between 25-35 weeks (mean: $29.7 \pm 3.6$ weeks) and the birth weights ranged from $595 \mathrm{~g}$ to $2150 \mathrm{~g}$ (mean: $1352 \pm 582 \mathrm{~g}$ ). The demographic and clinical characteristics of the infants are shown in Table II.

Two to five video recordings were taken for GMs assessment. Two infants had five recordings, seven infants had four recordings, seven infants 
Table II. Demographic and Clinical Characteristics of the Infants *

\begin{tabular}{lc}
\hline Gender (male/female), $\mathrm{n}$ & $8 / 14$ \\
\hline Gestational age (week), mean \pm SD & $29.7 \pm 3.6$ \\
Birth weight (g), mean \pm SD & $1352 \pm 582$ \\
Head circumference (cm), mean \pm SD & $26.8 \pm 2.2$ \\
APGAR score, mean \pm SD & $6 \pm 1$ \\
$\quad$ 1st minute & $8 \pm 1$ \\
$\quad$ th minute & \\
Type of pregnancy, n & 18 \\
$\quad$ Spontaneus & 4 \\
$\quad$ Assisted reproductive technology & \\
Type of birth, n & 3 \\
$\quad$ Vaginal & 19 \\
$\quad$ Cesarean section & \\
Multiple pregnancy, n & 19 \\
$\quad$ None & $4 * *$ \\
Respiratory distress syndrome, n & 1 \\
Pneumonia & 4 \\
Retinopathy of prematurity & 2 \\
Patent ductus arteriosus & 3 \\
Necrotizing enterocolitis & 4 \\
Neonatal sepsis & 3 \\
\hline
\end{tabular}

*A patient may be in more than one diagnosis

**An infant died

had three recordings, and six infants had two recordings. The GMs results of all infants are given in Table III.

\section{The GMs results were categorized into 3 groups:}

Group $1(\mathrm{n}=8)$ : Infants who had normal GMs in all recordings and were ultimately evaluated as "normal" (case no: 2,5,6,8,9,12,14,17).

Group $2(n=12)$ : Infants who had abnormal GMs during writhing movements period (PR and CS) but had normal GMs in subsequent recordings and were ultimately evaluated as "normal" (case no: 1,3,4,7,10,11,13,16,18,19 ,20,22).

Group $3(n=2)$ : Infants who had consistent PR and CS GMs and FMs were absent in the fidgety period. These infants were ultimately evaluated as "abnormal" (case no: 15,21).

The neurologic examination was completed at the corrected age of 12 months for all infants. Increased muscle tone in both of the upper and lower extremities (upper $=2$, lower $=3$ ) was found in one infant, while only in the lower extremities (lower $=3$ ) in another infant according to MAS. With the exception of these two infants, 20 had normal reflexes, muscle tone, and gross motor function. Complete agreement (kappa $=1)$ was found between GMs and the results of the neurologic examinations.

At the age of corrected 12 months, the GMFM and Bayley-III Scale were used to evaluate the infants. The scores of the GMFM and Bayley-III Scale of all infants are shown in Table IV. Two infants in group 3 (abnormal GMs results) also had lower GMFM and Bayley-III scores than the other infants.

The results of GMFM and Bayley-III Scale were compared between group 1 and group 2. We found statistically significant differences between the groups only in the "standing" parameter of GMFM $(\mathrm{p}<0.05)$ and "cognitive" parameter of the Bayley-III Scale $(p<0.05)$ (Table V). No statistically significant difference was found in other parameters between the groups.

One or more cranial ultrasonography images 
Table III. The results of GMs Assessment

\begin{tabular}{|c|c|c|c|c|c|c|}
\hline & $\begin{array}{l}\text { 1.record } \\
29-31 \text { weeks }\end{array}$ & $\begin{array}{l}\text { 2.record } \\
\text { 32-37 weeks }\end{array}$ & $\begin{array}{l}\text { 3.record } \\
38-44 \text { weeks }\end{array}$ & $\begin{array}{l}\text { 4.record } \\
48-50 \text { weeks }\end{array}$ & $\begin{array}{l}\text { 5.record } \\
50-55 \\
\text { weeks }\end{array}$ & \\
\hline Case no & \multicolumn{3}{|c|}{ Writhing movements } & \multicolumn{2}{|c|}{ Fidgety movements } & Results \\
\hline \multicolumn{7}{|l|}{ Group I } \\
\hline 2 & - & - & $\mathrm{N}$ & - & $\mathrm{N}$ & $\mathrm{N}$ \\
\hline 5 & $\mathrm{~N}$ & $\mathrm{~N}$ & - & $\mathrm{N}$ & $\mathrm{N}$ & $\mathrm{N}$ \\
\hline 6 & - & - & $\mathrm{N}$ & $\mathrm{N}$ & - & $\mathrm{N}$ \\
\hline 8 & - & $\mathrm{N}$ & $\mathrm{N}$ & $\mathrm{N}$ & - & $\mathrm{N}$ \\
\hline 9 & - & $\mathrm{N}$ & $\mathrm{N}$ & $\mathrm{N}$ & $\mathrm{N}$ & $\mathrm{N}$ \\
\hline 12 & - & - & - & $\mathrm{N}$ & $\mathrm{N}$ & $\mathrm{N}$ \\
\hline 14 & $\mathrm{~N}$ & $\mathrm{~N}$ & - & - & - & $\mathrm{N}$ \\
\hline 17 & $\mathrm{~N}$ & $\mathrm{~N}$ & $\mathrm{~N}$ & - & - & $\mathrm{N}$ \\
\hline \multicolumn{7}{|l|}{ Group II } \\
\hline 1 & PR & - & - & $\mathrm{N}$ & $\mathrm{N}$ & $\mathrm{N}$ \\
\hline 3 & PR & PR & - & $\mathrm{N}$ & $\mathrm{N}$ & $\mathrm{N}$ \\
\hline 4 & - & PR & PR & $\mathrm{N}$ & $\mathrm{N}$ & $\mathrm{N}$ \\
\hline 7 & CS & PR & $\mathrm{N}$ & $\mathrm{N}$ & $\mathrm{N}$ & $\mathrm{N}$ \\
\hline 10 & CS & $\mathrm{N}$ & - & $\mathrm{N}$ & - & $\mathrm{N}$ \\
\hline 11 & PR & $\mathrm{N}$ & - & - & - & $\mathrm{N}$ \\
\hline 13 & PR & $\mathrm{N}$ & - & - & $\mathrm{N}$ & $\mathrm{N}$ \\
\hline 16 & - & PR & $\mathrm{N}$ & - & - & $\mathrm{N}$ \\
\hline 18 & - & PR & $\mathrm{N}$ & $\mathrm{N}$ & $\mathrm{N}$ & $\mathrm{N}$ \\
\hline 19 & PR & PR & - & $\mathrm{N}$ & $\mathrm{N}$ & $\mathrm{N}$ \\
\hline 20 & CS & PR & - & $\mathrm{N}$ & $\mathrm{N}$ & $\mathrm{N}$ \\
\hline 22 & PR & $\mathrm{N}$ & $\mathrm{N}$ & - & - & $\mathrm{N}$ \\
\hline \multicolumn{7}{|l|}{ Group III } \\
\hline 15 & CS & CS & $\mathrm{CS}$ & F- & F- & AN \\
\hline 21 & CS & CS & - & - & F- & AN \\
\hline
\end{tabular}

N: Normal, AN: Abnormal, PR:"Poor Repertoire", CS:"Cramped-Synchronized", F-:"Absent Fidgety"

were obtained from each infant during hospitalization. The last cranial ultrasonography obtained before discharge was included in the study. However, the ultrasonography findings were not known and were reviewed from their data when infants reached the corrected age of 12 months. We compared cranial ultrasonography and GMs assessment, and significant agreement was found between GMs and cranial ultrasonography (kappa $=0.76)$.

\section{Discussion}

In our study, which aimed to evaluate GMs and compare the GMs assessment results with the findings of neurologic examinations, we demonstrated high consistency between GMs results and neurologic assessment in a group of high-risk, preterm LBW infants. A high degree of agreement was found between the results of GMs and neurologic examinations at the corrected age of 12 months.

Assessment of GMs is a non-invasive method that can be performed without expensive equipment ${ }^{11}$. The assessment of GMs may be useful in the determination of possible neurologic impairments that may occur in the future. The assessments are dependent on Gestalt perception of the observers ${ }^{19}$; therefore, 
Table IV. GMFM and Bayley-III Scores of all Infants

\begin{tabular}{ll}
\hline GMFM Scores, mean \pm SD & \\
\hline Supine-prone & $97.2 \pm 1.9$ \\
Sitting & $92.1 \pm 13.7$ \\
Crawling-kneeling & $77.3 \pm 10.5$ \\
Standing & $60.5 \pm 10.8$ \\
& \\
Bayley-III Scores, mean \pm SD & \\
Cognitive & $88.6 \pm 11.2$ \\
Gross motor & $84.8 \pm 12.9$ \\
Language & $85.8 \pm 14.8$ \\
\hline
\end{tabular}

GMFM: Gross Motor Function Measure

there have been some arguments about the subjective nature of the method. However, Valentin et al. $^{20}$ found the inter-observer reliability of GMs to be $90 \%$. Abnormal GMs, especially cramped-synchronized GMs, seem to be a predictor of permanent motor impairment ${ }^{4}$. Nakajima et al. ${ }^{21}$ studied 18 preterm infants with 22 weeks post-term age and concluded that the detailed score of poor repertoire GMs was not related to neurologic outcomes but indicated that FMs have specific predictive value for neurologic outcomes. In our study, PR GMs were not found predictive for neurologic outcomes and the infants with PR GMs developed normal FMs. CP was predicted through consistent and predominant CS GMs according to Ferrari et al. ${ }^{4}$. In the same study, the authors also indicated that it is wise to continue video recording when CS GMs became intermittant to determine whether they were transient or consistent, and whether FMs would appear. We followed-up infants who had persistent CS GMs during the FMs period. Cioni et al.3,22 showed that the results of GMs assessment were highly correlated with neurologic outcomes. According to a review ${ }^{23}$ there is good evidence that GMs assessment can accurately predict the development of CP. In our study, infants who had persistant abnormal GMs showed CP sypmtoms and those who had normal GMs demonstrated normal neurologic development at a corrected age of 12 months, which supports findings in the literature. Infants with CP symptoms were included in 2-year follow-up period and were diagnosed as having CP. One infant had level-II by Gross

Table V. The differences in GMFM and Bayley-III scores between Group 1 and Group 2

\begin{tabular}{llll}
\hline & $\begin{array}{l}\text { Group 1 }(\mathrm{n}=8) \\
\text { mean } \pm \text { SD }\end{array}$ & $\begin{array}{l}\text { Group 2 }(\mathrm{n}=12) \\
\text { mean } \pm \text { SD }\end{array}$ & $\mathrm{p}$ \\
\hline GMFM scores, mean \pm SD & & & \\
$\quad$ Supine-prone & 100 & 100 & 1.0 \\
$\quad$ Sitting & $99.3 \pm 1.9$ & $98.7 \pm 3.1$ & 0.851 \\
$\quad$ Crawling-kneeling & $81.3 \pm 11.3$ & $85.7 \pm 11.7$ & 0.305 \\
$\quad$ Standing & $80.2 \pm 16.7$ & $57.3 \pm 20.3$ & $0.025^{*}$ \\
& & & \\
Bayley-III scores, mean $\pm \mathrm{SD}$ & & & $0.047^{*}$ \\
Cognitive & $95 \pm 7.1$ & $86.6 \pm 8.3$ & 0.571 \\
$\quad$ Gross motor & $89.1 \pm 13$ & $85.6 \pm 8.5$ & 0.208 \\
$\quad$ Language & $91.8 \pm 3.5$ & $85.8 \pm 12.5$ & \\
\hline
\end{tabular}


Motor Function Classification Scale (GMFCS) and the other had level-V by GMFCS.

The provision of a developmental trajectory for each individual is the most important advantage of the GMs assessment, by indicating consistency or inconsistency of normal or abnormal findings. Ferrari et al. ${ }^{4}$ supported that infants with similar neurologic outcomes had similar developmental trajectories. In the same study, consistency in time or predominance from preterm birth to 5 months post-term age, specifically the CS character of GMs, was reported to determine development of subsequent CP. The authors also confirmed that normal FMs following transient abnormalities of GMs indicates a normal outcome, and absence of FMs suggest a neurologic deficiency. The predictive value of FMs period is known to be more effective than other periods. Several studies have demonstrated a relationship between the quality of GMs and neurologic outcomes during the FMs period $7,9,19,24$. The quality of FMs was shown to allow valid determinations about neurologic outcomes such as the first signs of spasticity by Prechtl et al. ${ }^{14}$. Similar to previous studies, we observed high consistency between FMs and neurologic outcomes. Infants who had normal FMs had normal neurologic outcomes.

Repeated recordings of GMs are more valuable in the neurodevelopmental follow-up of infants rather than single GMs recording 22,25 . In our study, we performed at least two and a maximum of five video recordings per infant from birth to 6 months. The absence of FMs is highly predictive for the development of CP and it is necessary to use at least one video recording and a second recording if FMs are not described in the first recording ${ }^{11}$. Nevertheless, Mutlu et al. ${ }^{10}$ showed high consistency between FMs and neurologic outcomes using only one recording. In our study, we tried to provide at least one recording during the FMs period at 48-55 weeks of gestation. Eleven infants had two video recordings, six had one video recording, and unfortunately, five had no video recordings in the FMs period. Two infants had absent FMs and the result of their neurologic examination was CP. Adde et al. ${ }^{26}$ evaluated 52 preterm and term infants' FMs recordings using computer-based software and they showed that using two video recordings rather than one improved the computer visionbased identification of FMs. We suggest that the computer-based method in detecting FMs would be helpful and easy in future studies.

Kodric et al. ${ }^{27}$ studied GMs of 26 preterm infants with 23-36 weeks gestational age and the results of GMs were compared with the results of the Bayley mental and psychomotor developmental index which was assessed between two and three years of chronologic age. The authors reported that infants with normal writhing GMs and normal FMs achieved the highest scores on the mental and psychomotor developmental index, while the infants with CS GMs. This was also true in our study, the infants who had no FMs had the lowest scores in all parameters of Bayley-III and GMFM. Bruggink et al. ${ }^{28}$ showed that the quality of GMs during early infancy for preterm children was a marker for intelligence at school age. They also reported when GMs normalized before term, IQ scores were within normal limits and when GMs were persistently abnormal until 8 weeks after term IQ scores were lower. In the present study, we also compared Bayley-III and GMFM results of infants who had persistent abnormal GMs (group 3), and those with abnormal GMs with normal GMs in subsequent recordings (group 2) at the corrected age of 12 months. A statistically significant difference was found in the "standing" parameter of GMFM $(p<0.05)$ and "cognitive" parameter of the Bayley-III Scale $(p<0.05)$. High-risk infants must be closely monitored, especially in developmental terms, because of their highrisk of growth retardation ${ }^{29}$. If we performed this comparison in earlier months, perhaps using other parameter (sitting, crawling, etc.) differences could occur. On the other hand, preterm infants with low scores could catch up with other infants by 12 months on the differences that we found between Bayley-III and GMFM scores in the future. We think future studies should focus on comparing results of long-term follow-up and with larger study groups.

Many studies detected the predictive value of GMs as high, as well as the neurologic assessment and cranial ultrasonography ${ }^{14,30}$. Seme-Ciglenecki ${ }^{31}$ showed that cranial ultrasonography had a lower sensitivity but almost the same specificity as GMs. Mutlu et 
al. ${ }^{10}$ found complete agreement (kappa $=0.86$ ) between cranial ultrasonography findings and GMs. Cioni et al. ${ }^{22}$ found $78-83 \%$ compliance between neurologic assessment and GMs. Our findings also supported these studies with significant agreement (kappa $=0.76)$ between cranial ultrasonography and GMs.

Many studies have reported a correlation between abnormal GMs and subsequent neurologic impairments, such as $\mathrm{CP}$ and minor neurologic deficits ${ }^{14,19,32-34}$. A limitation of our study was the inability for long-term follow-up of the infants. The other limitation of our study was that we could not recruit more patients, because it was difficult to convince the parents to join the study. We could not reassess and follow-up more infants because the parents were reluctant to bring their babies back to the hospital after a long hospitalization period in the NICU. Postpartum depression may have also had an effect on this unwillingness.

\section{Conclusion}

The assessment of the quality of GMs, especially CS GMs and FMs, can help to determine neurologic disorders in high-risk infants. In conclusion, we suggest the combination of neurologic examination, GMs, and other methods to detect neurologic impairment in high-risk, preterm LBW infants. Studies are needed with frequent follow-up examinations completed over a long-term period, with a high number of infants.

\section{Acknowledgements}

The authors give thanks to Monica Ann Malt and David Chapman for their editing support. The authors also wish to thank the staff of the Neonatal Care Unit, Faculty of Medicine of Istanbul University for their sincerity and helpfulness. We are grateful to Dr. İpek Alemdaroğlu for her critical reading of the article.

\section{REFERENCES}

1. Fawke J. Neurological outcomes following preterm birth. Semin Fetal Neonatal Med 2007; 12: 374-382.

2. Can $G$, Coban $A$, Ince $Z$, Ozmen $M$. Yenidoğan ve hastalıkları. İçinde: Neyzi O, Ertugrul T, (eds). Pediyatri ( $\left.{ }^{4} \mathrm{ed}\right)$. İstanbul: Nobel Tip Kitabevleri; 2010: 335-505.

3. Cioni G, Ferrari F, Einspieler C, Paolicelli PB, Barbani MT, Prechtl HF. Comparison between observation of spontaneous movements and neurologic examination in preterm infants. J Pediatr 1997; 130: 704-711.
4. Ferrari F, Cioni G, Einspieler C, Roversi MF, Bos AF, Paolicelli PB, et al. Cramped synchronized general movements in preterm infants as an early marker for cerebral palsy. Arch Pediat Adolesc Med 2002; 156: 460-467.

5. Bruggink JL, Einspieler C, Butcher PR, Van Braeckel KN, Prechtl HF, Bos AF. The quality of the early motor repertoire in preterm infants predicts minor neurologic dysfunction at school age. J Pediatr 2008; 153: 32-39.

6. Bruggink JL, Einspieler C, Butcher PR, Stremmelaar EF Prechtl HF, Bos AF. Quantitative aspects of the early motor repertoire in preterm infants: Do they predict minor neurological dysfunction at school age? Early Hum Dev 2009; 85: 25-36.

7. Adde L, Rygg M, Lossius K, Oberg GK, Stoen R. General movement assessment: Predicting cerebral palsy in clinical practise. Early Hum Dev 2007; 83: 13-18.

8. Romeo DM, Guzzetta A, Scoto M, Cioni M, Patusi P, Mazzone D, et al. Early neurologic assessment in preterm-infants: Integration of traditional neurologic examination and observation of general movements. Eur J Paediatr Neurol 2008; 12: 183-189.

9. Burger M, Frieg A, Louw QA. General movements as a predictive tool of the neurological outcome in very low and extremely low birth weight infants - A South African perspective. Early Hum Dev 2011; 87: 303-308.

10. Mutlu A, Livanelioglu A, Korkmaz A. Assessment of "general movements" in high-risk infants by Prechtl analysis during early intervention period in the first year of life. Turk J Pediatr 2010; 52: 630-637.

11. Einspieler C, Prechtl HF, Bos AF, Ferrari F, Cioni G. Prechtl's Method on the Qualitative Assessment of General Movements in Preterm, Term and Young Infants. London: Mac Keith Press; 2004.

12. Einspieler C, Bos AF, Libertus ME, Marschik PB. The General Movement Assessment Helps Us to Identify Preterm Infants at Risk for Cognitive Dysfunction. Front Psychol 2016; 7.

13. Bennema AN, Schendelaar P, Seggers J, Haadsma ML Heineman MJ, Hadders-Algra M. Predictive value of general movements' quality in low-risk infants for minor neurological dysfunction and behavioural problems at preschool age. Early Hum Dev 2016; 94: 19-24.

14. Prechtl HF, Einspieler C, Cioni G, Bos AF, Ferrari F, Sontheimer D. An early marker for neurological deficits after perinatal brain lesions. Lancet 1997; 349: 13611363.

15. Scholtes VA, Becher JG, Beelen A, Lankhorst GJ. Clinical assessment of spasticity in children with cerebral palsy: a critical review of available instruments. Dev Med Child Neurol 2006; 48: 64-73.

16. Russell DJ, Rosenbaum PL, Cadman DT, Gowland C, Hardy S, Jarvis S. The gross motor function measure - a means to evaluate the effects of physical therapy. Dev Med Child Neurol 1989; 31: 341-352.

17. Greene MM, Patra K, Nelson MN, Silvestri JM. Evaluating preterm infants with the Bayley-III: Patterns and correlates of development. Res Dev Disabil 2012; 33: 1948-1956. 
18. Şenocak MŞ. Klinik Biyoistatistik. İstanbul: Nobel Tıp Kitabevleri; 2009.

19. Hadders-Algra M. General movements: A window for early identification of children at high risk for developmental disorders. J Pediatr 2004; 145: S12-S8.

20. Valentin T, Uhl K, Einspieler C. The effectiveness of training in Prechlt's method on the qualitative assessment of general movements. Early Hum Dev 2005; 81: 623-637.

21. Nakajima Y, Einspieler C, Marschik PB, Bos AF, Prechtl HF. Does a detailed assessment of poor repertoire general movements help to identify those infants who will develop normally? Early Hum Dev 2006; 82: 5359.

22. Cioni G, Prechtl HF, Ferrari F, Paolicelli PB, Einspieler C, Roversi MF. Which better predicts later outcome in fullterm infants: quality of general movements or neurological examination? Early Hum Dev 1997; 50: 71-85.

23. Bosanquet M, Copeland L, Ware R, Boyd R. A systematic review of tests to predict cerebral palsy in young children. Dev Med Child Neurol 2013; 55: 418-426.

24. Yuge M, Marschik PB, Nakajima Y, Yamori Y, Kanda $\mathrm{T}$, Hirota $\mathrm{H}$, et al. Movements and postures of infants aged 3 to 5 months: To what extent is their optimality related to perinatal events and to the neurological outcome? Early Hum Dev 2011; 87: 231-237.

25. Einspieler C, Prechtl HF, Ferrari F, Cioni G, Bos AF. The qualitative assessment of general movements in preterm, term and young infants - Review of the methodology. Early Hum Dev 1997; 50: 47-60.

26. Adde L, Helbostad J, Jensenius AR, Langaas M, Stoen R. Identification of fidgety movements and prediction of $\mathrm{CP}$ by the use of computer-based video analysis is more accurate when based on two video recordings. Physiother Theory Pract 2013; 29: 469-475.
27. Kodric J, Sustersic B, Paro-Panjan D. Assessment of general movements and 2.5 year developmental outcomes: pilot results in a diverse preterm group. Eur J Paediatr Neurol 2010; 14: 131-137.

28. Bruggink JL, Van Braeckel KN, Bos AF. The Early Motor Repertoire of Children Born Preterm Is Associated With Intelligence at School Age. Pediatrics 2010; 125: E1356-E1363.

29. Bayoglu BU. Riskli bebeklerde gelişimsel gecikmenin değerlendirilmesi. İçinde : Akman İ, (ed). Riskli bebek izlemi. İstanbul: Boyut; 2014: 110-119.

30. Maas YG, Mirmiran M, Hart AA, Koppe JG, Ariagno RL, Spekreijse H. Predictive value of neonatal neurological tests for developmental outcome of preterm infants. J Pediatr 2000; 137: 100-106.

31. Seme-Ciglenecki P. Predictive values of cranial ultrasound and assessment of general movements for neurological development of preterm infants in the Maribor region of Slovenia. Wiener klin Wochenschr 2007; 119: 490-496.

32. Einspieler C, Prechtl HF. Prechtl's assessment of general movements: a diagnostic tool for the functional assessment of the young nervous system. Ment Retard Dev Disabil Res Rev 2005; 11: 61-67.

33. Ferrari F, Cioni G, Prechtl HF. Qualitative changes of general movements in preterm infants with brain lesions. Early Hum Dev 1990; 23: 193-231.

34. Hadders-Algra M, Groothuis AM. Quality of general movements in infancy is related to neurological dysfunction, ADHD, and aggressive behaviour. Dev Med Child Neurol 1999; 41: 381-391. 